\title{
NÍVEL DE DISCLOSURE NOS RELATÓRIOS DE SUSTENTABILIDADE EM CONFORMIDADE COM O GLOBAL REPORTING INITIATIVE (GRI)
}

\section{LEVEL OF DISCLOSURE IN SUSTAINABILITY REPORTS IN COMPLIANCE WITH GLOBAL REPORTING INITIATIVE (GRI)}

\begin{abstract}
DANIELA DI DOMENICO
Mestra em Ciências Contábeis pela FURB. Professora no Curso de Ciências Contábeis da Universidade Comunitária da Região de Chapecó (UNOCHAPECÓ). Endereço: Avenida Senador Attílio Fontana, 591 E, Bloco R, EFAPI | 89809000 / Chapecó/SC / Brasil.

E-mail: didomenico@unochapeco.edu.br
\end{abstract}

\section{LIDIANE TORMEM}

Bacharela em Ciências Contábeis pela Universidade Comunitária da Região de Chapecó (UNOCHAPECO). Endereço: Avenida Senador Attílio Fontana, 591 E, Bloco R, EFAPI | 89809000 / Chapecó/SC / Brasil.

E-mail: lidiane-tormem@auroraalimentos.com.br

\section{SADY MAZZIONI}

Doutor em Ciências Contábeis e Administração pela FURB. Professor no Mestrado em Ciências Contábeis e Administração da Universidade Comunitária da Região de Chapecó (UNOCHAPECÓ). Endereço: Avenida Senador Attílio Fontana, 591 E, Bloco R, EFAPI | 89809000 | Chapecó/SC / Brasil.

E-mail: sady@unochapeco.edu.br

\section{RESUMO}

O objetivo do artigo é analisar o nível de disclosure nos relatórios de sustentabilidade em conformidade com o Global Reporting Initiative (GRI) nas empresas listadas na BM\&FBovespa. Nesse sentido, realizou-se pesquisa descritiva com procedimentos de coleta documental e abordagem quantitativa. A amostra analisada ficou composta por 93 empresas listadas na BM\&FBovespa, que divulgaram o relatório de sustentabilidade no ano de 2014 em conformidade com o modelo GRI. Os resultados mostram que à medida em que há maior complexidade nas informações, que compreendem os grupos de indicadores apresentados nos relatórios de sustentabilidade, reduz o nível de evidenciação pelas empresas. Com relação ao nível de evidenciação, percebe-se que o maior grupo de empresas se concentra com baixa evidenciação. Representa cerca de $30 \%$ das empresas analisadas, atendendo até 50 itens dos 150 que o relatório propõe. Quanto ao setor econômico, utilidade pública apresentou maior nível de evidenciação nos relatórios de sustentabilidade em conformidade com o modelo GRI. Conclui-se que, embora tenha havido aumento na divulgação dos relatórios de sustentabilidade, as empresas ainda carecem de adaptação para atender aos indicadores do GRI, melhorando a qualidade dos relatórios divulgados e elevando a transparência aos diversos públicos de interesse.

Palavras-chave: Responsabilidade socioambiental. Relatórios de sustentabilidade. GRI. 


\begin{abstract}
The objective of the study is to analyze the level of disclosure in the sustainability reports in compliance with the Global Reporting Initiative (GRI) in the companies listed on the $B M \& F B o v e s p a$. In this sense, a descriptive research was carried out with procedures of documentary collection and quantitative approach. The sample analyzed was composed of 93 companies listed on the BM\&FBovespa, which published the sustainability report in 2014 in compliance with the GRI model. The results show that to the extent that there is more complexity in the information that comprises the groups of indicators presented in the sustainability reports, it reduces the level of disclosure by companies. Regarding the level of disclosure, it is noticed that the largest group of companies is concentrated with low disclosure, representing around 30\% of the analyzed companies, attending up to 50 items out of the 150 that the report proposes. As for the economic sector, public utility presented a higher level of disclosure in sustainability reports in compliance with the GRI model. It is concluded that, although there has been an increase in the dissemination of sustainability reports, companies still need adaptation to meet the GRI indicators, improving the quality of the reports disseminated and increasing the transparency of the various stakeholders.
\end{abstract}

Keywords: Social and environmental responsibility. Sustainability reports. GRI.

\title{
1 INTRODUÇÃO
}

A responsabilidade ambiental das organizações produtivas está sendo discutida de forma intensa recentemente e uma parcela da sociedade se tornou mais exigente com a origem e a sustentabilidade dos produtos. Adicionalmente, as empresas têm sido demandadas quanto à responsabilidade com a utilização dos recursos naturais e com os impactos ambientais da sua atividade.

Problemas ambientais como as alterações climáticas, o esgotamento de recursos, a escassez da água e a poluição do ar, entre outros, têm um grande impacto sobre a Terra e seus habitantes. Todos esses fatores têm levado a população a se conscientizar da importância dos recursos naturais para reverter o processo de degradação ambiental (Sartori, Ensslin, Campo \& Ensslin, 2014).

A responsabilidade social e ambiental é entendida como um conjunto de ações voltadas para a estratégia gerencial das empresas, visando ao seu comprometimento com os recursos naturais e ao mesmo tempo contribuindo com o desenvolvimento econômico. $O$ avanço tecnológico permitiu o surgimento de mecanismos capazes de inserir as informações sociais e ambientais no processo gerencial das empresas. Compõem um artefato de competitividade no segmento de atuação (Lima, Cunha, Morreira, \& Porte, 2012).

Os movimentos em favor da sustentabilidade fizeram com que as responsabilidades sociais e ambientais ganhassem maior destaque nos últimos tempos, gerando maior preocupação nas diversas áreas do conhecimento. Essas áreas passaram a trabalhar o assunto observando o envolvimento de toda a sociedade na busca por soluções que não prejudiquem o meio ambiente (Martins, Quintana, Jacques, \& Machado, 2013).

O desenvolvimento de gestão ambiental é um passo importante, pois induz as empresas às práticas sustentáveis e a garantir melhor qualidade de vida à sociedade. Evidenciar a gestão ambiental por meio de relatórios possibilita vantagem competitiva, pois demonstra as atividades que a empresa empreende e é fundamental para que a sua imagem diante da sociedade não seja negligenciada (Bauer \& Naime, 2012).

Devido às necessidades de as empresas demonstrarem a preocupação com os recursos naturais e os efeitos que suas atividades exercem sobre o meio ambiente, 0 comprometimento com a transparência e responsabilidade socioambiental tornou-se imprescindível para evitar desperdícios e degradações. Os relatórios de evidenciação tornamse importantes instrumentos para informar a sociedade e demais interessados sobre a responsabilidade e conscientização da gestão de recursos naturais e o seu uso racional. 
Assim, tornou-se necessária uma contabilidade adequada para esses registros (Freitas \& Oleiro, 2011).

Os relatórios que registram as responsabilidades sociais e ambientais geram transparência na execução de suas atividades, demonstram maior envolvimento da empresa com a sociedade, possibilitam benefícios para a comunidade em geral e para os recursos naturais que estarão sendo preservados (Mazzioni, Di Domenico, \& Zanin, 2010).

Para os usuários, os relatórios funcionam como mecanismo de avaliação das práticas desenvolvidas na sociedade. As informações sociais e ambientais evidenciadas permitem construir instrumentos capazes de medir e controlar as consequências, como os custos e benefícios provenientes das ações socioambientais desempenhadas pela empresa (Holanda, Cardoso, Oliveira, \& Luca, 2012).

A partir do contexto apresentado, pretende-se responder ao seguinte problema de pesquisa: Qual o nível de disclosure nos relatórios de sustentabilidade em conformidade com o Global Reporting Initiative (GRI)? O objetivo do estudo é analisar o nível de disclosure nos relatórios de sustentabilidade em conformidade com o Global Reporting Initiative (GRI). Como objetivos específicos, foram considerados: (i) Identificar o nível de evidenciação em cada grupo de indicadores sugeridos pelo GRI; (ii) Analisar a evidenciação das empresas, segregando-as em grupos de acordo com o nível de evidenciação e por setor econômico de atuação; (iii) Avaliar a capacidade dos diferentes níveis de governança corporativa influenciem na evidenciação socioambiental; (iv) Verificar a existência de fatores explicativos para o nível de evidenciação observado na amostra investigada.

O estudo demonstra como as empresas estão evidenciando as práticas ambientais, sociais e econômicas na sua gestão e como essas informações são apresentadas aos stakeholders. O artefato mais completo para a evidenciação é o relatório proposto pelo GRI, que serve como ferramenta de auxílio para a tomada de decisão, padronização das informações e comparabilidade.

Justifica-se a importância do estudo, em função da crescente preocupação da sociedade com a preservação do meio ambiente. Esse é um dos motivos pelos quais as empresas precisam inovar e investir nas práticas sustentáveis, para garantir a credibilidade dos consumidores, investidores e, sobretudo, da própria sociedade. Para tanto, torna-se necessário que as empresas divulguem as práticas ambientais e sociais, além do gerenciamento dos impactos ambientais causados (Di Domenico, Mazzioni, Gubiani, Kronbauer, \& Vilani, 2015). A gestão ambiental é importante como ferramenta de diferenciação de mercado, pois demonstra a preocupação com os recursos naturais, os efeitos negativos proporcionados à sociedade e a preocupação com a perenidade da entidade.

A adequada evidenciação das práticas sociais e ambientais pode agregar valor às organizações, pois, além de promover a transparência das informações, possibilita aumentar a comunicação e reduzir a discrepância com as suas contrapartes. A evidenciação é importante ferramenta de gestão interna e controle. Estabelece padrões de documentos ambientais, além de contemplar uma estratégia organizacional (Rosa, Ensslin, Ensslin \& Lunkes, 2011). O GRI é o modelo mais utilizado, por ajudar as empresas a compreender e comunicar os impactos causados ao meio ambiente de forma transparente a seus usuários (Global Reporting Initiative [GRI], 2015).

Além da introdução, o artigo apresenta mais quatro seções. A seção dois aborda a revisão da literatura, que está dividida em três subseções: sustentabilidade ambiental, evidenciação ambiental e estudos correlatos. A seção três apresenta os procedimentos metodológicos; a seção quatro demonstra a análise dos resultados e a seção cinco delineia as conclusões e pesquisas futuras.

\section{REVISÃO DA LITERATURA}

A subvenção de sustentabilidade socioambiental demonstra o comprometimento das empresas com o meio ambiente e a sociedade. A subseção de sustentabilidade ambiental demonstra os conceitos em torno da gestão ambiental e seus impactos ao meio ambiente. A subseção de evidenciação ambiental aborda a importância da divulgação das práticas desenvolvidas pelas empresas e o impacto da sua imagem perante a sociedade. E, por fim, a subseção de estudos correlatos apresenta resultados obtidos em pesquisas similares. 


\subsection{Sustentabilidade socioambiental}

Sustentabilidade ambiental refere-se a formas inovadoras de reduzir os impactos causados ao meio ambiente, por meio de atividades que não agridam os recursos naturais e beneficiem a sua conservação. A palavra sustentabilidade normalmente é relacionada com o meio ambiente, mas também engloba aspectos sociais e econômicos, que, interligados, buscam o equilíbro ao longo do tempo (Nogueira \& Faria, 2012).

Medeiros, Souza, Franzin, Almeida e Souza (2013) entendem a sustentabilidade ambiental como o processo de desenvolvimento da empresa, sem afetar os recursos naturais existentes no local e que de nenhuma forma possam gerar escassez e extinção, agravando o desequilíbrio ou promovendo agressões da essencialidade de preservação da vida.

A sustentabilidade é medida por meio da capacidade da empresa em movimentar os recursos naturais de uma forma inovadora, sem prejudicar os recursos existentes, buscando materiais alternativos que não impactem em seus custos e preservem o meio ambiente (Tomé \& Bresciani, 2015).

Caracteriza-se como sustentabilidade uma gestão eficiente, responsável e sustentável, que gera benefício para todas as partes interessadas, que utiliza seus recursos ou investe financeiramente para evitar danos negativos ao meio ambiente e preservá-lo de forma adequada, que trabalha com uma boa operacionalidade da preservação do meio ambiente (Holanda et al., 2012).

Dessa forma, a sustentabilidade possibilita garantir, preservar, conservar e assegurar os recursos naturais por um longo período de tempo. Satisfaz às necessidades presentes dos seres vivos e fornece continuação das necessidades futuras das próximas gerações (Pereira, Pereira, Monteiro, \& Paixão, 2015).

Já responsabilidade social faz com que a empresa repense sua missão institucional e a forma de conduzir seus negócios corporativos, buscando manter-se no mercado globalizado, em que se trabalha com a postura ética, transparente e responsável nas atividades exercidas. Empresa com atuação de responsabilidade social é aquela que oferece seus produtos e serviços pensando na preservação do meio ambiente e desenvolvimento sustentável, não somente cumprindo as leis, mas atuando da melhor forma, priorizando informações para gestão com qualidade (Holanda et al., 2012).

Buscando eliminar os efeitos negativos do crescimento econômico na natureza, a sustentabilidade está ligada à preservação dos recursos naturais e à autorregulação do consumo desses recursos. Tem como principal objetivo melhorar a qualidade de vida e usar de forma adequada os recursos renováveis (Siche, Agostinho, Ortega, \& Romeiro, 2007).

A expressão sustentabilidade passou por constante evolução. Ganhou interpretação no meio econômico, ou seja, não é apenas garantir recursos ambientais para as gerações futuras sobreviverem, mas atuar de forma a controlar os danos que ocorrem com sua degradação, fazer com que as empresas promovam a preservação ambiental, aplicando de forma justa suas riquezas para atingir sua eficiência econômica (Bauer \& Naime, 2012).

A sustentabilidade reflete uma política de desenvolvimento econômico e social, sem gerar prejuízos ao ambiente e seus recursos naturais. A qualidade da conservação e continuidade depende das atividades humanas. Esse desenvolvimento exige a preservação do equilíbrio global. Reflete nos efeitos socioeconômicos. A sociedade necessita evitar desperdícios e o esgotamento das reservas naturais (Rodrigues \& Duarte, 2011). Sustentabilidade é o modo de suprir as necessidades humanas sem prejudicar o futuro das próximas gerações (Santos, 2014).

A visão da sociedade e clientes vem se modificando. Passa a avaliar e a criticar a degradação que ocorre no meio ambiente, causado pelas empresas. Se bem empregada, a sustentabilidade pode se tornar estratégica para a empresa. Pode diminuir seus custos com a reutilização de materiais, aumentar suas vendas e conquistar clientes que optam por empresas sustentáveis. Essa preocupação da sociedade e clientes com a sustentabilidade tende a gerar mudanças em busca de melhor qualidade de vida das gerações futuras (Scarpin, Walter, Mondini, \& Roncon, 2013).

As empresas passaram a ter sua atenção voltada para a sustentabilidade. Trabalham sobre as questões sociais, ambientais e econômicas, desempenham um papel importante 
como agentes participantes no desenvolvimento sustentável, criam estratégias para contribuição e satisfação da sustentabilidade (Nobre \& Ribeiro, 2013).

Também é constante a busca por melhorias no setor produtivo que visem à preservação dos recursos naturais, observando ações de recuperação do ambiente que foi degradado com suas atividades e desenvolvendo educação ambiental para funcionários, terceiros e para a comunidade em geral (Freitas \& Oleiro, 2011).

A adoção da gestão socioambiental influencia os colaboradores e consumidores com relação à preservação dos recursos ambientais e a como manter esses recursos para futuras gerações com qualidade de vida sustentável, garantindo o bem-estar da sociedade como um todo (Freitas \& Oleiro, 2011).

As empresas têm a necessidade de implantar políticas ambientais para diminuir ou eliminar a agressão ao meio ambiente, que é causada por meio das atividades exercidas. Mas isso não se resume somente às práticas das políticas ambientais. É necessária a divulgação para a sociedade dessas informações relatando impactos, objetivos e metas que pretendem alcançar. A relação da empresa com a sociedade deve ser de transparência. Deve mostrar a real situação que as atividades exercem no ambiente. Deve averiguar quando ocorrer qualquer problema, evitando gerar riscos, pressões ou julgamentos por parte da sociedade (Carneiro, De Luca, \& Oliveira, 2008).

As empresas que trabalhavam com relatórios exclusivamente financeiros passaram a perceber a importância de elaborar relatórios de sustentabilidade, para tornar pública sua visão, desafios e resultados sociais, ambientais e econômicos, e, assim, possibilitar interação com a sociedade (Mazzioni, Di Domenico, \& Zanin, 2010). A forma mais comum de relatar informações sobre a sustentabilidade é por meio dos relatórios específicos. Apesar desses tipos de relatórios assumirem diferentes títulos, relacionam-se à mesma temática (Carreira \& Palma, 2012).

As práticas de sustentabilidade estão sendo utilizadas não somente pelas empresas, mas pela sociedade, que está em busca constante da melhor qualidade de vida. Essas práticas evitam efeitos danosos causados ao meio ambiente, trazem inovações de reutilização, pois diminuem as agressões e preservam os recursos naturais. Por isso, são necessárias as práticas sustentáveis e a elaboração de relatórios destinados à conservação do meio ambiente.

\subsection{Evidenciação socioambiental}

As empresas vêm divulgando relatórios de evidenciação socioambiental, não somente pelo interesse no cumprimento das normas, mas para preservar sua imagem e demonstrar transparência, proporcionando informações eficazes para os diversos usuários.

A evidenciação socioambiental é um meio utilizado pelas empresas para atender às exigências da comunidade internacional, necessária para gerar informações aos governos, acionistas, administradores, funcionários, entre outros usuários. Essas informações estão disponíveis em websites e em relatórios anuais das empresas (Silva, Vicente, Pfitscher, \& Rosa, 2013).

No Brasil, embora as empresas divulguem os relatórios de sustentabilidade, seu processo ainda é embrionário, pois há falta de adequação no aspecto contábil. Isso gera deficiência na evidenciação e impede que a empresa tenha um melhor gerenciamento de suas questões ambientais. Além disso, priva os usuários de informações que possam auxiliar a conhecer a empresa com maior profundidade (Carneiro, De Luca, \& Oliveira, 2008).

Dessa forma, não há legislação no Brasil que obrigue as empresas a divulgar as demonstrações de práticas ambientais e sociais. São visíveis as empresas que evidenciam voluntariamente seus relatórios de sustentabilidade (Di Domenico \& Lavarda, 2013).

A empresa tem a opção de divulgar determinadas informações, as quais não são exigidas por lei. Desse modo, cada empresa age conforme a concepção dos seus gestores. Podem proporcionar aos usuários informações suficientes para que compreendam as atividades desenvolvidas e seus riscos (Beuren, Nascimento, \& Rocha, 2013). As informações evidenciadas voluntariamente demonstram que as empresas se preocupam com as melhorias e a manutenção de resultados (Borges, Rosa, \& Ensslin, 2010).

A divulgação voluntária significa a não obrigatoriedade legal na divulgação das informações ambientais nos relatórios desenvolvidos pela empresa no decorrer dos exercícios, porém não é tarefa fácil aos administradores escolherem quais informações disponibilizar. A 
falta de qualquer das informações pode levar a questionamentos referentes à forma de controle das questões ambientais e sociais, afetar direta e indiretamente os negócios da entidade. A sociedade só terá conhecimento das informações ambientais se a empresa estiver comprometida com a transparência e a veracidade dos fatos que ocorrem (Boff \& Beuren, 2012).

A preocupação com questões socioambientais e a divulgação dessas informações interferem nas organizações como uma atitude ética. As empresas precisam detalhar seu desempenho aos usuários e divulgar informações com transparência. Se assim não o fizerem, poderão prejudicar a continuidade da empresa, ocasionar perdas no mercado para as demais, que demonstram aspectos ambientais em seus relatórios (Pereira, Carvalho, \& Parente, 2011).

Para a evidenciação ser uma informação eficiente, é necessário que a gestão e o desempenho da empresa sejam revelados. Esses aspectos incluem informações de contas patrimoniais, de resultado, de emissões, socioambientais, consumo de recursos naturais, entre outras, que devem ser demonstradas em seus relatórios. A falta dessas informações poderá acarretar em perda de mercado e credibilidade (Rosa et al., 2011).

Com a falta de padronização nos relatórios de sustentabilidade abre-se um espaço para que as empresas escolham livremente o tipo de relatório para a utilização das evidenciações sociais e ambientais, resultantes das atividades produtivas (Cavalcanti, Almeida, Almeida, \& Limeira, 2009). Para dar respostas à sociedade, as empresas necessitam de instrumentos para divulgar suas informações, atividades desenvolvidas e de como isso afeta o meio ambiente. Essas informações passam a ser demonstradas, por meio de relatórios, que abordem se a empresa possui condições financeiras para assegurar a longevidade sem destruir o meio ambiente (Guimarães, Rech, Cunha, \& Pereira, 2014).

O relatório mais utilizado atualmente é o Global Reporting Initiative (GRI), que possui padrão internacional e ajuda as organizações a compreender e comunicar os impactos da empresa sobre questões sustentáveis. Os relatórios do modelo GRI utilizam normas padronizadas de informação, descrevem os impactos econômicos, ambientais e sociais. Além disso, aumentam tanto a comparabilidade como a qualidade da informação disponível para as partes interessadas, permitem melhor decisão entre a relação das atividades da empresa e seu impacto sobre o desenvolvimento sustentável (GRI, 2015).

O GRI é uma organização internacional com a missão de desenvolver e disseminar relatórios de sustentabilidade. Essa organização ajuda a compreender e a comunicar os impactos ambientais. Contribui para a padronização das informações e verifica a conformidade com os relatórios apresentados pelas empresas (GRI 2016).

Com a crescente preocupação da sociedade com o meio ambiente, os relatórios de sustentabilidade servem de instrumentos de apoio na tomada de decisão, além de mostrar a preocupação com os efeitos negativos que suas atividades exercem sobre os recursos naturais. Por isso, é necessário evidenciar nos relatórios o desempenho ambiental, mostrar a preocupação e garantir melhor qualidade de vida para as gerações futuras.

\subsection{Estudos correlatos}

Este tópico apresenta estudos correlatos, com abordagens semelhantes, que demonstram como as empresas têm evidenciado em seus relatórios as questões ambientais e sua preocupação com a degradação dos recursos.

Beuren et al. (2013) verificaram a relação entre o nível de evidenciação ambiental e o desempenho econômico de empresas de capital aberto classificadas no Guia Você S/A - As Melhores Empresas para Você Trabalhar. Os resultados da pesquisa mostram que: a) na categorização da evidenciação ambiental, 680 informações foram evidenciadas, distribuídas em 99 informações completas, 126 informações incompletas e 455 informações ausentes; b) no nível de pontuação da evidenciação ambiental, 55\% das empresas receberam conceito insuficiente, $35 \%$ regular e $9 \%$ bom e c) a relação entre o nível de evidenciação ambiental e o desempenho econômico das empresas apresentou correlação fraca. Concluiu-se, ao utilizar a metodologia Análise Envoltória de Dados (DEA), que nem todas as empresas que apresentaram maior nível de evidenciação das informações ambientais obtiveram desempenho econômico eficiente. 
Beuren, Di Domenico e Cordeiro (2013) investigaram o comportamento de indicadores do Environmental Management Accounting (EMA), evidenciados no Global Reporting Initiative (GRI), de empresas do setor de papel e celulose listadas na BM\&FBovespa. Os resultados demonstram que a Suzano Papel e Celulose S.A. apresentou eficiência ao longo do período, comparados o volume de recursos materiais, água e energia consumida e o volume de produção gerado. A Klabin S.A. foi ganhando eficiência no período, particularmente a partir de 2008. A Celulose Irani S.A. baixou sua eficiência em 2008 e 2009 e apresentou recuperação em 2010. Concluíram que os indicadores físicos do EMA, evidenciados no GRI de 2006 a 2010, sinalizam que essas empresas vêm buscando maior eficiência no uso dos recursos naturais, o que é importante para garantir o futuro das próximas gerações.

Miranda e Malaquias (2013) analisaram o nível de disclosure ambiental fornecido pelas companhias brasileiras de capital aberto em suas demonstrações contábeis. Os resultados mostraram que o nível de evidenciação ambiental aumentou com o decorrer do tempo. Por meio da análise de correlações, verificou-se que a variável tamanho apresentou correlação positiva e moderada com os níveis de evidenciação de 2005 e 2010. Por meio do Teste de Student, foi possível verificar se as entidades de setores regulamentados evidenciam mais informações ambientais do que as constantes em setores não regulamentados. Os resultados mostraram que as empresas de setores regulamentados expõem mais informações ambientais em relação às pertencentes aos setores não regulamentados. Em seguida, foi realizada a análise de variância. Pode-se verificar que o nível de governança das empresas não possui relação direta com os níveis de evidenciação.

Santos, Silva, Lorandi (2014) examinaram o nível de evidenciação ambiental das companhias listadas na BM\&FBovespa, pertencentes ao segmento de energia elétrica. Identificou-se que dentre as 65 companhias listadas nesse segmento, 75\% (49 empresas) divulgaram o relatório socioambiental correspondente ao ano de 2011. A Agência Nacional de Energia Elétrica (ANEEL) orienta que as empresas publiquem o balanço social (modelo IBASE) dentro dos relatórios socioambientais. No entanto, constatou-se que somente 49 empresas da amostra o divulgaram. Os resultados da pesquisa apontaram que 34 empresas evidenciaram $90 \%$ ou mais dos itens analisados, 28 delas descreveram todos nos relatórios. Concluiu-se que a intervenção do órgão regulador impulsiona as empresas do setor elétrico brasileiro a prestar contas à sociedade, tendo em vista que os recursos naturais são essenciais para operacionalização das atividades exercidas.

Di Domenico et al. (2016) identificam os determinantes do nível de disclosure nos relatórios de sustentabilidade, em conformidade com o Global Reporting Initiative (GRI), nas empresas listadas na BM\&FBovespa. Os resultados apontam que à medida em que há maior complexidade nos itens que compreendem os grupos de indicadores dos relatórios de sustentabilidade em conformidade com o modelo GRI, reduz-se o nível de evidenciação das empresas. O setor de utilidade pública apresentou maior nível de evidenciação nos relatórios de sustentabilidade em conformidade com o modelo GRI. Os determinantes para o nível de evidenciação foram: riqueza gerada, margem líquida, retorno sobre o patrimônio líquido e retorno sobre o ativo.

Os resultados das pesquisas evidenciaram que as empresas têm assumido preocupação com o meio ambiente. Introduziram a evidenciação ambiental em seus relatórios, mesmo ainda carecendo de adequações. As empresas buscam melhorar a transparência e seus resultados ano após ano, para atender às expectativas das partes interessadas. Devem, pois, fornecer informações que beneficiem sua imagem perante o mercado e garantir melhor qualidade de vida às próximas gerações.

\section{PROCEDIMENTOS METODOLÓGICOS}

Nesta seção, são apresentados os métodos e procedimentos utilizados para a realização da pesquisa. Quantos aos objetivos o estudo caracteriza-se como descritivo, devido as seu aprofundamento estar baseado na análise das características informacionais dos relatórios de sustentabilidade das empresas listadas na BM\&FBovespa. Em relação aos procedimentos, a pesquisa baseou-se na análise documental, por examinar os relatórios de sustentabilidade das empresas compostas na amostra. E quanto à abordagem do problema é quantitativa, pelo emprego de técnicas estatísticas para análise e interpretação dos dados. 
A população da pesquisa foi composta por 757 empresas listadas na BM\&FBovespa e a amostra contempla 93 empresas que divulgaram o relatório de sustentabilidade no ano de 2014, baseado no modelo GRI. Foram excluídas as empresas financeiras dado que as políticas contábeis e financeiras, as estratégias corporativas e a forma de operação possuem peculiaridades diferentes das demais organizações.

$\mathrm{O}$ instrumento da coleta de dados foi construído por meio de um check list em consonância com as exigências do modelo internacional GRI versão G4, composto por 150 indicadores, divididos em 13 grupos. A análise considerou algumas características das empresas analisadas, no intuito de verificar a existência de diferenças no nível de evidenciação, conforme demonstrado na Figura 1.

\begin{tabular}{|c|c|c|}
\hline VARIÁVEL & MÉTRICA & FONTE \\
\hline $\begin{array}{l}\text { Evidenciação } \\
\text { socioambiental }\end{array}$ & $\begin{array}{l}\text { Total de pontos obtidos em relação ao total de indicadores } \\
\text { sociais e ambientais da GRI 4. Atribui-se } 1 \text { para as } \\
\text { informações evidenciadas plenamente; } 0,5 \text { para informações } \\
\text { parcialmente evidenciadas; e } 0 \text { para as informações não } \\
\text { evidenciadas. }\end{array}$ & $\begin{array}{l}\text { Relatórios anuais e/ou } \\
\text { de sustentabilidade, } \\
\text { modelo GRI. }\end{array}$ \\
\hline Governança corporativa & $\begin{array}{l}\text { Grupo } 1 \text { = empresas do grupo tradicional; } \\
\text { Grupo 2= empresas listadas no IGCX; }\end{array}$ & BM\&FBovespa \\
\hline Endividamento & $\begin{array}{l}\text { Grupo } 1 \text { = empresas com endividamento abaixo da mediana; } \\
\text { Grupo 2= empresas com endividamento acima da mediana; }\end{array}$ & Economática \\
\hline $\begin{array}{l}\text { Concentração de } \\
\text { propriedade }\end{array}$ & $\begin{array}{l}\text { Grupo } 1 \text { = empresas com concentração abaixo da mediana; } \\
\text { Grupo 2= empresas com concentração acima da mediana; }\end{array}$ & Economática \\
\hline Comitê de auditoria & $\begin{array}{l}\text { Grupo } 1 \text { = empresas que não possuem comitê de auditoria; } \\
\text { Grupo 2= empresas que possuem comitê de auditoria; }\end{array}$ & BM\&FBovespa \\
\hline $\begin{array}{l}\text { Presença de investidor } \\
\text { institucional }\end{array}$ & $\begin{array}{l}\text { Grupo } 1 \text { = empresas em que os investidores institucionais } \\
\text { possuem participação acionária de até } 5 \% \text {; } \\
\text { Grupo 2= empresas com investidor institucional cuja } \\
\text { participação acionária é superior a } 5 \% \text {; }\end{array}$ & BM\&FBovespa \\
\hline $\begin{array}{c}\text { Internacionalização das } \\
\text { empresas }\end{array}$ & $\begin{array}{l}\text { Grupo } 1 \text { = empresas que não possuem emissão de ADR's; } \\
\text { Grupo 2= empresas que possuem emissão de ADR's; }\end{array}$ & BM\&FBovespa \\
\hline Tamanho & $\begin{array}{l}\text { Grupo } 1 \text { = empresas com tamanho abaixo da mediana; } \\
\text { Grupo 2= empresas com tamanho acima da mediana; }\end{array}$ & Economática \\
\hline
\end{tabular}

Figura 1. Variáveis do estudo

Fonte: Elaborado pelos autores.

A Figura 1, apresenta as principais características estudadas com relação à divulgação dos relatórios de sustentabilidade, em que a variável dependente utilizada é composta pelos indicadores propostos pelo GRI e as variáveis independentes referem-se às características organizacionais.

Para a análise dos dados utilizou-se: (i) medidas da estatística descritiva, para identificar o desempenho das empresas investigadas quanto aos níveis de evidenciação socioambiental; (ii) teste Kolmogorov-Smirnov (KS) para verificar a normalidade dos dados; (iii) teste de Levene para verificar igualdade de variâncias; (iv) teste t para igualdade de médias e teste ANOVA para identificar a existência de diferenças na evidenciação das informações a partir das distintas características empresariais. As análises foram elaboradas por meio do uso do software Statistical Package for the Social Sciences (SPSS ${ }^{2}$ ).

\section{ANÁLISE E INTERPRETAÇÃO DOS RESULTADOS}

Esta seção apresenta o nível de evidenciação dos indicadores propostos pelo Global Reporting Initiative (GRI) nos relatórios de sustentabilidade das empresas listadas na BM\&FBovespa. O GRI permite extrair dados da evidenciação ambiental das empresas, gerar informações relevantes aos usuários, melhorar o gerenciamento do desempenho ambiental e auxiliar na tomada de decisão no sentido de identificar as práticas que podem ser melhoradas.

Para atender ao objetivo específico de identificar o nível de evidenciação em cada grupo de indicadores sugeridos pelo GRI, apresentam-se os resultados consolidados no Gráfico 1. A subdivisão é dada em treze grupos: estratégia e análise; perfil organizacional; aspectos materiais e limites; engajamento de stakeholders; perfil do relatório, governança; ética e 
integridade; desempenho econômico; desempenho ambiental; desempenho social; direitos humanos; sociedade e responsabilidade pelo produto.

\section{\% de Evidenciação}

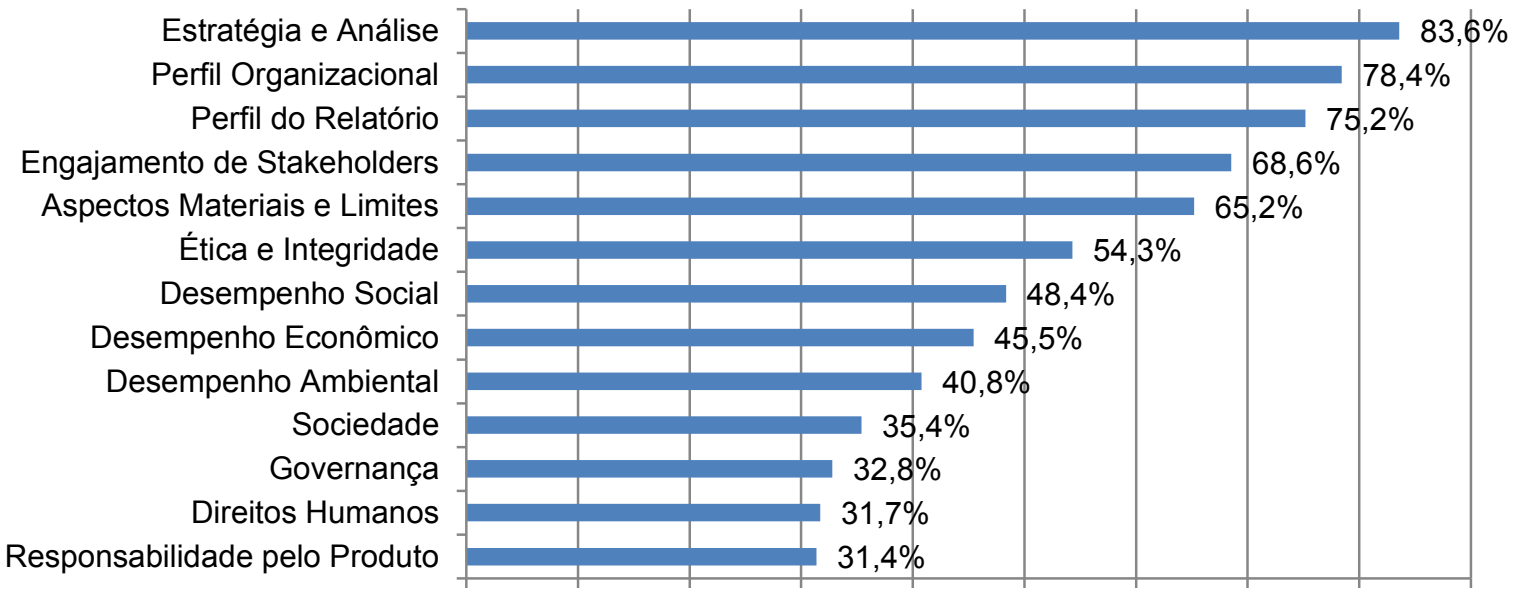

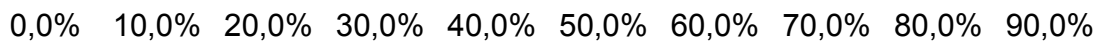

Figura 2. Nível de evidenciação socioambiental por grupo de indicadores Fonte: Dados da pesquisa.

A Figura 2 demonstra que os grupos de indicadores que apresentam maior nível de evidenciação são: estratégia e análise $(83,6 \%)$, perfil organizacional $(78,4 \%)$ e perfil do relatório $(75,2 \%)$. Uma possível explicação para o elevado nível de evidenciação está relacionada ao caráter de informações cadastrais, como o nome da organização, principais produtos/serviços, localização da sede, países em que opera, mercados de atuação, porte da organização, relevância da sustentabilidade, principais impactos, riscos e oportunidades, período coberto pelo relatório, data do relatório anterior, ciclo de emissão e dados para contato.

$\mathrm{Na}$ sequência destacam-se os grupos dos indicadores de engajamento de stakeholders $(68,6 \%)$, aspectos materiais e limites $(65,2 \%)$ e ética e integridade (54,3\%). O nível de evidenciação pode estar relacionado à baixa complexidade das informações, incluída a divulgação de processo adotado para definir o conteúdo do relatório, o limite dentro e fora da organização, aspectos de materiais identificados, grupos de stakeholders engajados na organização, base para identificação, seleção e abordagem da organização para engajar stakeholders, princípios, valores, normas de comportamento e como as organizações comunicam preocupações em torno de comportamentos não éticos ou incompatíveis com a legislação.

Os demais indicadores, como desempenho social, desempenho econômico, desempenho ambiental, sociedade, governança, direitos humanos e responsabilidade pelo produto apresentaram baixo nível de evidenciação, com média abaixo de $50 \%$. Dessa forma, percebe-se que as empresas evidenciam de forma parcial as informações socioambientais, o que denota a necessidade de ampliação dessas práticas que indicam o compromisso social das empresas.

Os grupos de indicadores de desempenho social, direitos humanos, sociedade e responsabilidade pelo produto detalham os impactos da organização sobre os sistemas sociais em que atuam. Abrangem informações referentes ao aspecto empregatício, práticas trabalhistas, saúde e segurança no trabalho, treinamento e educação, diversidade e igualdade de oportunidades, liberdade de associação e negociação coletiva, avalição de fornecedores, impacto à corrupção, políticas públicas, concorrência desleal, segurança e saúde de clientes, privacidade dos clientes e conformidade com leis e regulamentos.

O grupo de indicadores de desempenho econômico trata dos impactos da organização sobre as condições econômicas dos stakeholders e o sistema econômico local, nacional e global. O grupo de indicadores de desempenho ambiental demonstra os impactos da organização sobre o ecossistema, incluídos o solo, o ar e a água. Já a governança apresenta sua estrutura e composição, o papel desempenhado pelo mais alto órgão de governança na definição do propósito, valores e estratégia da organização, gestão de riscos e na elaboração 
dos relatórios de sustentabilidade. O resultado indica que as empresas não estão adentrando nas questões ambientais, sociais, de governança, direito humanos e responsabilidade pelo produto, o que prejudica o resultado dos relatórios e sinaliza aos usuários da informação fragilidades no compromisso social.

Comparadas com o estudo de Di Domenico, Dal Magro, Mazzioni, Preis e Klann (2016), as questões relacionadas com direitos humanos, desempenho ambiental e responsabilidade pelo produto apresentam baixa evidenciação. Demonstram como as empresas não estão adentrando nesses assuntos e que relatam de forma parcial à medida em que há maior complexidade das informações. No estudo de Beuren et al. (2013), a evidenciação ambiental apresentou informações em sua predominância incompletas. Corroboram o baixo nível de evidenciação por parte das empresas.

De forma geral, pode-se inferir a partir do Gráfico 1 que quanto maior a complexidade nos itens que compreendem os grupos de indicadores apresentados nos relatórios de sustentabilidade em conformidade com o modelo GRI, menor é o nível de evidenciação pelas empresas, ou seja, quanto mais complexas as informações, maior a probabilidade de não ocorrer a divulgação completa.

Contudo, está aumentando o número de empresas que utilizam os relatórios de sustentabilidade, apesar das informações serem apresentadas de forma parcial no que diz respeito aos indicadores do modelo GRI.

Para atender ao objetivo de analisar a evidenciação das empresas, segregando-as em grupos de acordo com o nível de evidenciação e por setor econômico de atuação, foram elaboradas as Tabelas 1 e 2.

A Tabela 1 apresenta o nível médio de evidenciação das empresas, conforme a distribuição aos grupos e o número de itens evidenciados, a partir do checklist elaborado em observância ao modelo do GRI. A lista de verificação contemplou 150 itens. Para cada empresa estudada foi atribuído pontuação de 0 a 150.

Em seguida, as empresas foram agrupadas de acordo com a pontuação obtida, obedecidas as seguintes escalas de evidenciação: Grupo 1 - de 0 a 50 itens atendidos (baixa), Grupo 2 - de 51 a 75 itens atendidos (média), Grupo 3 - de 76 a 100 itens atendidos (alta) e o Grupo 4 - acima de 100 itens atendidos (superior).

Tabela 1

Evidenciação dos indicadores por grupos de empresas

\begin{tabular}{c|c|c|c}
\hline Nível de Evidenciação & $\mathrm{N}^{\circ}$ Empresas & \% médio de empresas & $\mathrm{N}^{\circ}$ médio de itens evidenciados \\
\hline Grupo 1 & 28 & $30,11 \%$ & 33 \\
Grupo 2 & 27 & $29,03 \%$ & 64 \\
Grupo 3 & 24 & $25,81 \%$ & 89 \\
Grupo 4 & 14 & $15,05 \%$ & 123 \\
\hline
\end{tabular}

Nota. Fonte: Dados da pesquisa.

A Tabela 1 demonstra a evidenciação dos indicadores por grupos de empresas. A maior concentração se encontra no Grupo 1. Representa 30\% das empresas analisadas. O número de itens atendidos varia de 0 a 50 dos 150 observados. Representa baixa evidenciação. Os resultados demonstram que as empresas divulgam de modo inferior os itens compostos nos relatórios. Não atendem à complexidade dos demais indicadores.

O grupo 4 contém as empresas que atendem adequadamente aos itens dos relatórios, ou seja, em torno de $15 \%$ das empresas analisadas evidenciaram em média 123 dos 150 itens observados. Dessa forma, essas empresas estão trabalhando de forma ética, transparente e responsável. Demonstram sua preocupação com os recursos ambientais.

Esses resultados corroboram os apresentados por Beuren et al. (2013) que indicam que as informações evidenciadas nos relatórios de sustentabilidade, na sua predominância, são ausentes. Representam um conceito insuficiente de evidenciação e não atendem aos critérios exigidos pelo modelo GRI.

A Tabela 2 mostra o nível médio de evidenciação geral, segregadas as empresas de acordo com os setores econômicos. 
Tabela 2

Nível médio de evidenciação dos 150 indicadores do modelo GRI em relação aos setores

\begin{tabular}{c|c|c|c|c|c}
\hline \multicolumn{2}{c}{ Setores de Atuação } & \multicolumn{3}{c}{ Nível de Evidenciação Geral } \\
\cline { 2 - 6 } & Percentual & Grupo 1 & Grupo 2 & Grupo 3 & Grupo 4 \\
\hline Petróleo, Gás e & $3,57 \%$ & $3,70 \%$ & $4,17 \%$ & $7,14 \%$ \\
Biocombustível & Número & 1 & 1 & 1 & 1 \\
\hline \multirow{2}{*}{ Materiais Básicos } & Percentual & $7,14 \%$ & $14,82 \%$ & $12,50 \%$ & $14,29 \%$ \\
& Número & 2 & 4 & 3 & 2 \\
\hline \multirow{2}{*}{ Bens Industriais } & Percentual & $7,14 \%$ & $7,41 \%$ & $29,17 \%$ & $14,29 \%$ \\
& Número & 2 & 2 & 7 & 2 \\
\hline \multirow{2}{*}{ Consumo Não Cíclico } & Percentual & $14,30 \%$ & $18,52 \%$ & $4,17 \%$ & $14,29 \%$ \\
& Número & 4 & 5 & 1 & 2 \\
\hline \multirow{2}{*}{ Consumo Cíclico } & Percentual & $35,71 \%$ & $22,22 \%$ & $0,00 \%$ & $7,14 \%$ \\
& Número & 10 & 6 & 0 & 1 \\
\hline \multirow{2}{*}{ Saúde } & Percentual & $7,14 \%$ & $3,70 \%$ & $4,17 \%$ & $0,00 \%$ \\
& Número & 2 & 1 & 1 & 0 \\
\hline \multirow{2}{*}{ Tecnologia da Informação } & Percentual & $3,57 \%$ & $0,00 \%$ & $0,00 \%$ & $0,00 \%$ \\
& Número & 1 & 0 & 0 & 0 \\
\hline \multirow{2}{*}{ Telecomunicações } & Percentual & $0,00 \%$ & $7,41 \%$ & $8,32 \%$ & $0,00 \%$ \\
& Número & 0 & 2 & 2 & 0 \\
\hline \multirow{2}{*}{ Utilidade Pública } & Percentual & $21,43 \%$ & $22,22 \%$ & $37,50 \%$ & $42,85 \%$ \\
& Número & 6 & 6 & 9 & 6 \\
\hline \multirow{2}{*}{ TOTAL } & Percentual & $\mathbf{1 0 0} \%$ & $\mathbf{1 0 0} \%$ & $\mathbf{1 0 0} \%$ & $\mathbf{1 0 0 \%}$ \\
& No Empresas & $\mathbf{2 8}$ & $\mathbf{2 7}$ & $\mathbf{2 4}$ & $\mathbf{1 4}$ \\
\hline
\end{tabular}

Nota. Fonte: Dados da pesquisa.

A Tabela 2 demonstra o nível de evidenciação em relação aos setores econômicos, separados em quatro grupos: 1 (baixa evidenciação), 2 (média evidenciação), 3 (alta evidenciação) e 4 (elevada evidenciação). Demonstra os setores de atuação que apresentam maior evidenciação e os que precisam se adequar às exigências do GRI, proporcionando maior transparência a seus stakeholders.

Os resultados apresentados na Tabela 2 mostram que das 14 empresas que divulgaram seus relatórios de sustentabilidade com evidenciação superior, $42,85 \%$ concentram-se no setor de utilidade pública; $14,29 \%$ no setor de materiais básicos, consumo não cíclico e consumo cíclico, respectivamente. Das 24 empresas que apresentaram alto nível de evidenciação nos relatórios de sustentabilidade, a maior concentração está no setor de utilidade pública $(37,50 \%)$, no setor de consumo $(29,17 \%)$ e materiais básicos $(12,50 \%)$. Das 27 empresas que apresentaram média evidenciação nos relatórios de sustentabilidade, a maior concentração das empresas está nos setores de consumo cíclico e utilidade pública, com $(22,22 \%)$, respectivamente. Em seguida aparece o setor de consumo não cíclico (18,52\%) e materiais básicos $(14,82 \%)$. Por fim, das 28 empresas que demonstraram baixa evidenciação nos relatórios de sustentabilidade em conformidade com o modelo $\mathrm{GRI}, 35,71 \%$ concentram-se no setor de consumo cíclico; $21,43 \%$ no de utilidade pública; $14,30 \%$ no de consumo não cíclico; $7,14 \%$ em materiais básicos, bens industriais e saúde e $3,57 \%$ no setor de petróleo, gás e biocombustível e tecnologia da informação.

Os resultados indicam que a intervenção de órgão regulador impulsiona as empresas do setor público a divulgarem informações à sociedade, tendo em vista que os recursos são essenciais para a operacionalização das atividades exercidas. Com isso, o setor de utilidade pública apresenta maior nível de evidenciação.

A aplicação dos testes estatísticos observou os resultados obtidos no teste Kolmogorov - Smirnov (KS) para as variáveis quantitativas, a saber: concentração de propriedade, endividamento, tamanho e o índice de evidenciação, conforme evidenciado na Tabela 3. 
Tabela 3

Teste Kolmogorov-Smirnov para normalidade dos dados

\begin{tabular}{|c|c|c|c|c|c|}
\hline & & CONC & END & Ln_TAM & IE \\
\hline \multicolumn{2}{|l|}{$\mathrm{N}$} & 93 & 93 & 93 & 93 \\
\hline \multirow{2}{*}{ Parâmetros Normais } & Média & 52,55 & 0,62 & 6,85550645 & 69,9839 \\
\hline & Desvio padrão & 24,906 & 0,208 & 0,634037747 & 32,49435 \\
\hline \multirow{3}{*}{$\begin{array}{l}\text { Diferenças Extremas } \\
\text { Máximas }\end{array}$} & Absolutas & 0,097 & 0,086 & 0,053 & 0,051 \\
\hline & Positivas & 0,097 & 0,086 & 0,053 & 0,051 \\
\hline & Negativas & $-0,082$ & $-0,046$ & $-0,026$ & $-0,045$ \\
\hline \multicolumn{2}{|l|}{ Kolmogorov-Smirnov Z } & 0,940 & 0,831 & 0,507 & 0,488 \\
\hline \multicolumn{2}{|c|}{ Significância assintótica ( 2 caudas) } & 0,340 & 0,495 & 0,960 & 0,971 \\
\hline
\end{tabular}

Nota. Fonte: Dados da pesquisa.

A partir dos resultados da Tabela 3, confirmada a normalidade dos dados, pode-se trabalhar com testes de natureza paramétrica para analisá-los.

Outro objetivo do estudo é o de avaliar se a capacidade dos diferentes níveis de governança corporativa influencia na evidenciação socioambiental. Para verificar a existência de diferenças no nível de evidenciação socioambiental em relação aos distintos níveis de governança corporativa, utilizou-se a técnica da análise de variância (ANOVA) com o teste de Tukey, conforme evidenciado na Tabela 4.

Tabela 4

Resultados ANOVA pelas comparações múltiplas do Teste de Tukey de acordo com o NGC

\begin{tabular}{|c|c|c|c|c|c|c|}
\hline \multirow{2}{*}{ (I) NDGC } & \multirow{2}{*}{ (J) NDGC } & \multirow{2}{*}{$\begin{array}{l}\text { Diferença } \\
\text { média (I-J) }\end{array}$} & \multirow{2}{*}{$\begin{array}{l}\text { Modelo } \\
\text { padrão }\end{array}$} & \multirow{2}{*}{ Significância } & \multicolumn{2}{|c|}{ Intervalo de confiança $95 \%$} \\
\hline & & & & & Limite inferior & Limite superior \\
\hline \multirow{3}{*}{1} & 2 & $-9,86979$ & 11,02661 & 0,807 & $-38,7401$ & 19,0005 \\
\hline & 3 & $-7,07813$ & 12,87631 & 0,946 & $-40,7914$ & 26,6352 \\
\hline & 4 & $-12,03239$ & 7,68380 & 0,403 & $-32,1504$ & 8,0856 \\
\hline \multirow{3}{*}{2} & 1 & 9,86979 & 11,02661 & 0,807 & $-19,0005$ & 38,7401 \\
\hline & 3 & 2,79167 & 14,86828 & 0,998 & $-36,1371$ & 41,7204 \\
\hline & 4 & $-2,16260$ & 10,69145 & 0,997 & $-30,1554$ & 25,8302 \\
\hline \multirow{3}{*}{3} & 1 & 7,07813 & 12,87631 & 0,946 & $-26,6352$ & 40,7914 \\
\hline & 2 & $-2,79167$ & 14,86828 & 0,998 & $-41,7204$ & 36,1371 \\
\hline & 4 & $-4,95427$ & 12,59048 & 0,979 & $-37,9192$ & 28,0107 \\
\hline \multirow{3}{*}{4} & 1 & 12,03239 & 7,68380 & 0,403 & $-8,0856$ & 32,1504 \\
\hline & 2 & 2,16260 & 10,69145 & 0,997 & $-25,8302$ & 30,1554 \\
\hline & 3 & 4,95427 & 12,59048 & 0,979 & $-28,0107$ & 37,9192 \\
\hline
\end{tabular}

Nota. Fonte: Dados da pesquisa.

$\mathrm{Na}$ análise da Tabela 4, as empresas foram segregadas em quatro grupos: 1 empresas com nível 1 de governança; 2 - empresas com nível 2 de governança; 3 - empresas do novo mercado; 4 - empresas do mercado tradicional.

O resultado obtido com a ANOVA, a partir das comparações múltiplas do teste Tukey, demonstra que não existem diferenças significativas no índice de evidenciação e os níveis de governança corporativa. As empresas listadas da BM\&FBovespa que aderem de forma voluntária aos níveis de governança corporativa, tendem a publicar um maior número de informações que vão além de regras e exigências de evidenciação.

O estudo de Gallon, Beuren e Hein (2007) apresentou relação entre o grau de evidenciação e o nível de governança das empresas. Em contrapartida, Gonçalves, Weffort, 
Peleias e Gonçalves (2008) e Cong e Freedman (2011) demonstram que o nível de governança das empresas parece não influenciar na relação.

Para verificar a existência de fatores explicativos para o nível de evidenciação, observado na amostra investigada, foram utilizados testes paramétricos. A partir da normalidade na distribuição dos dados das variáveis quantitativas, constatada por meio do teste K-S (Tabela 3), realizou-se a aplicação do teste de Levene para igualdade de variâncias e o teste-t para igualdade de médias. Os resultados estão apresentados na Tabela 5 e Tabela 6.

Inicialmente, a Tabela 5 apresenta as estatísticas de evidenciação para cada segregação de grupo de características empresariais, descritas no Quadro 1.

Tabela 5

\section{Estatísticas de grupo}

\begin{tabular}{|c|c|c|c|c|c|}
\hline Características & Grupo & $\mathrm{N}$ & Média & Desvio padrão & Erro padrão da média \\
\hline \multirow[t]{2}{*}{ COM_AUDIT } & 1 & 26 & 62,3654 & 31,86363 & 6,24897 \\
\hline & 2 & 67 & 72,9403 & 32,48875 & 3,96913 \\
\hline \multirow[t]{2}{*}{ INV_INST } & 1 & 41 & 75,5122 & 31,06254 & 4,85115 \\
\hline & 2 & 52 & 65,6250 & 33,22677 & 4,60772 \\
\hline \multirow[t]{2}{*}{ INTER } & 1 & 63 & 72,3333 & 33,00440 & 4,15816 \\
\hline & 2 & 30 & 65,0500 & 31,36392 & 5,72624 \\
\hline \multirow[t]{2}{*}{ NGC } & 1 & 32 & 62,7969 & 30,90356 & 5,46303 \\
\hline & 2 & 61 & 73,7541 & 32,91791 & 4,21471 \\
\hline \multirow[t]{2}{*}{ CONC } & 1 & 46 & 71,3478 & 33,43748 & 4,93009 \\
\hline & 2 & 47 & 68,6489 & 31,84847 & 4,64558 \\
\hline \multirow[t]{2}{*}{ END } & 1 & 46 & 68,1630 & 33,79334 & 4,98256 \\
\hline & 2 & 47 & 71,7660 & 31,43313 & 4,58499 \\
\hline \multirow[t]{2}{*}{ TAM } & 1 & 46 & 65,7391 & 34,74090 & 5,12227 \\
\hline & 2 & 47 & 74,1383 & 29,92358 & 4,36480 \\
\hline
\end{tabular}

Nota. Fonte: Dados da pesquisa.

Os resultados apresentados na Tabela 5 indicam que as empresas com comitê de auditoria, que não possuem investidor institucional, que não possuem emissão de ADR's, com nível diferenciado de governança corporativa, com maior concentração de capital, com maior nível de endividamento e com maiores valores de ativos apresentaram níveis mais elevados de evidenciação.

A verificação da existência de significância estatística nas diferenças médias encontradas na Tabela 5 foi realizada a partir do teste de Levene (para verificar a igualdade de variâncias), seguido do teste t para amostras independentes, conforme apresentado na Tabela 6, utilizando as características empresariais destacadas no Quadro 1. Quando o teste de Levene se mostrar com significância estatística $(<0,05)$ deve-se considerar as variâncias iguais como não assumidas. Caso contrário, considerar as variâncias iguais assumidas.

Os resultados obtidos não permitiram identificar quaisquer diferenças significativas entre os grupos de empresas constituídos conforme os critérios definidos. Uma possível explicação para os resultados é que a preocupação com a evidenciação ambiental está em patamar semelhante de consideração, independente das características operacionais das empresas.

Tabela 6

Teste de Levene e teste-t de médias

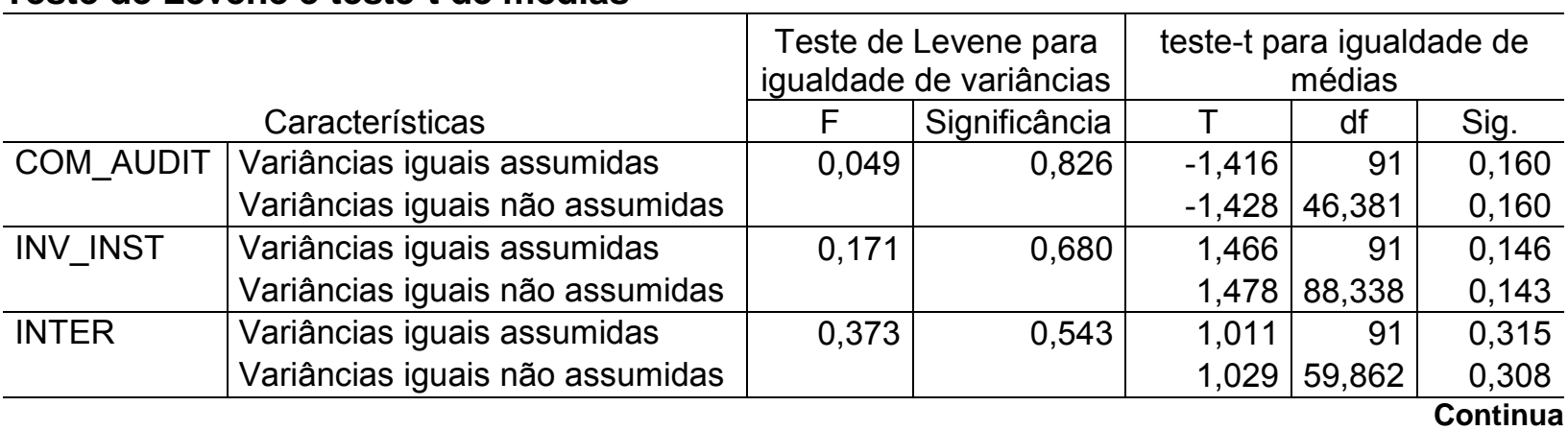


Tabela 6 (continuação)

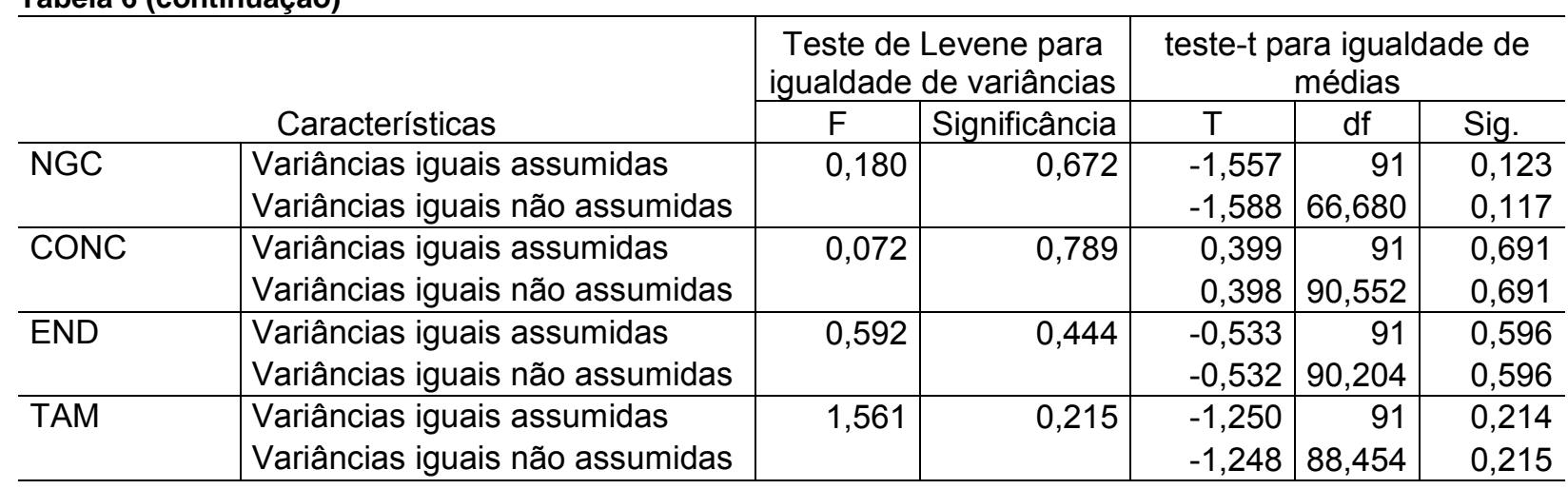

Nota. Fonte: Dados da pesquisa.

A partir das análises realizadas, nota-se que apesar do número de empresas que divulgam os relatórios de sustentabilidade ter aumentado no decorrer dos anos, as empresas estão divulgando de forma parcial as informações nos seus relatórios de sustentabilidade. Evidenciam informações cadastrais e deixam de apresentar informações mais complexas. Prejudicam o resultado do relatório e a sua relevância perante os usuários.

Os relatórios socioambientais possuem uma condição importante para melhorar a imagem das empresas perante a sociedade, a partir das informações propostas pelos modelos. Contudo, é relevante divulgar não somente informações cadastrais, mas abranger informações mais complexas. As empresas precisam se conscientizar e adotar práticas sustentáveis, atuar de forma a controlar os danos ao meio ambiente e garantir recursos ambientais para as futuras gerações.

\section{CONCLUSÃO}

O estudo teve por objetivo analisar o nível de disclosure nos relatórios de sustentabilidade em conformidade com o Global Reporting Initiative (GRI). Desse modo, a pesquisa se caracteriza como descritiva, com análise documental e quantitativa. Foi desenvolvida em uma amostra de 93 empresas listadas na BM\&FBovespa que divulgaram o relatório de sustentabilidade no ano de 2014, baseado no modelo GRI.

Os resultados apontados pelo estudo permitem concluir que à medida em que há maior complexidade nas informações que compreendem os grupos de indicadores apresentados nos relatórios de sustentabilidade em conformidade com o GRI, reduz-se o nível de evidenciação pelas empresas. Assim, a complexidade das informações de determinado item é relacionada com a possibilidade de não ocorrer tal divulgação, enquanto indicadores mais convencionais (a exemplo de dados cadastrais) são evidenciados com êxito, devido à facilidade na divulgação dos dados.

Com relação ao nível de evidenciação dos indicadores por grupos de empresas, percebe-se que grande parte evidencia de modo inferior itens compostos nos relatórios de sustentabilidade. Não atendem a totalidade dos indicadores. Por outro lado, há empresas que evidenciam voluntariamente e com qualidade os indicadores nos relatórios. Demonstram sua preocupação com o meio ambiente e trabalham de forma ética, transparente e responsável.

Diferente do esperado, os níveis mais elevados de governança corporativa não conduziram as empresas para níveis mais elevados de evidenciação socioambiental. Em relação ao setor de atuação, observou-se que as empresas reguladas, predominantemente do setor de utilidade pública, impulsionaram o nível de evidenciação em conformidade com o modelo GRI, constituindo-se em fator de distinção. Observa-se que a análise da evidenciação por setor foi realizada apenas em termos descritivos, uma vez que o número de empresas por grupo e por setor não permitiu uma análise inferencial.

A evidenciação dos relatórios de sustentabilidade é importante para as organizações, pois permite construir credibilidade, confiança e transparência aos stakeholders, além de 
demonstrar sua preocupação com os recursos naturais. Embora o número de empresas com o relatório disponível tenha crescido em comparação com estudos anteriores, as informações ainda são apresentadas de forma parcial, não abrangem a totalidade dos indicadores compostos no modelo GRI.

Os resultados apresentaram indícios de que as empresas maiores, com comitê de auditoria, que não possuem investidor institucional, que não possuem emissão de ADR's, com nível diferenciado de governança corporativa, com maior concentração de capital e com maior nível de endividamento, apresentaram níveis mais elevados de evidenciação. Contudo, as diferenças para suas contrapartes não foram significativas.

Com base na pesquisa realizada, propõe-se que sejam realizados novos estudos para analisar o desempenho dos indicadores ambientais em setores com forte dependência da produção de recursos naturais. Adicionalmente, pode-se utilizar outras características empresariais para justificar o nível de evidenciação.

\section{REFERÊNCIAS}

Bauer, M. M., \& Naime, R. (2012). Estado da arte da evidenciação social e ambiental voluntária. Revista de Administração, Contabilidade e Sustentabilidade, 2(2), 39-60.

Beuren, I. M., Di Domenico, D., \& Cordeiro, A. (2013). Análise dos indicadores do Environmental Management Accounting evidenciados no Global Reporting Initiative. Revista Gestão Organizacional, 6(2), 21-35.

Beuren, I. M., Nascimento, S., \& Rocha, I. (2013). Nível de evidenciação ambiental e desempenho econômico de empresas: aplicando a análise envoltória de dados. Future Studies Research Journal: Trends and Strategies, 5(1),198-226.

Boff, M. L., \& Beuren, I. M. (2012). Termos ambientais e sociais nos relatórios da administração. Pretexto, 13(2), 9-27.

Borges, A. P., Rosa, F. S., \& Ensslin, S. R. (2010). Evidenciação voluntária das práticas ambientais: um estudo nas grandes empresas brasileiras de papel e celulose. Produção, 20(3), 404-417.

Carneiro, J. E., De Luca, M. M. M., \& Oliveira, M. C. (2008). Análise das Informações Ambientais Evidenciadas nas Demonstrações Financeiras das Empresas Petroquímicas Brasileiras listadas na Bovespa. Revista Contabilidade Vista e Revista, 19(3), 39-67.

Carreira, F. A., \& Palma, C. M. (2012). Análise comparativa dos relatórios de sustentabilidade das empresas brasileiras, espanholas, portuguesas e Andorra. Revista Universo Contábil, 8(4), 140-166.

Cavalcanti, G. H., Almeida, K. K. N., Almeida, S. R., \& Limeira, M. P. (2009). Divulgação de informações contábeis ambientais das empresas brasileira do setor de utilidade pública: um estudo sobre o grau de aderência as normas brasileiras de contabilidade. Revista Sociedade, Contabilidade e Gestão, 4(2), 104-118.

Cong, Y., \& Freedman, M. (2011). Corporate governance and environmental performance and disclosure. Advances in Accounting, incorporating Advances in International Accounting, 27(1), 223-232.

Di Domenico, D., Dal Magro, C. B., Mazzioni, S., Preis, M. B., \& Klann, R. C. (2016). Determinantes do nível de disclosure nos relatórios de sustentabilidade em conformidade com o Global Reporting Initiative. Revista Gestão \& Sustentabilidade Ambiental, 4(2), 430.

Di Domenico, D., \& Lavarda, C. E. F. (2013). Características das empresas de capital aberto e os indicadores da contabilidade de gestão ambiental (CGA). Anais do Congresso Brasileiro De Custos, Uberlândia, MG, Brasil, 10. 
Di Domenico, D., Mazzioni, S., Gubiani, C. A., Kronbauer, N. B., \& Vilani, L. (2015). Práticas de responsabilidade socioambiental nas empresas de capital aberto de Santa Catarina listadas na BM\&FBovespa. Revista Catarinense da Ciência Contábil, 14(42), 70-84.

Freitas, D. P. S., \& Oleiro W. N. (2011). Contabilidade ambiental: a evidenciação nas demonstrações financeiras das empresas listadas na BM\&F Bovespa. REUNIR - Revista de Administração, Contabilidade e Sustentabilidade, 1(2), 65-81.

Gallon, A. V., Beuren, I. M., \& Hein, N. (2007). Análise da Relação entre Evidenciação nos Relatórios da Administração e o nível de Governança das Empresas na BOVESPA. Revista de Informação Contábil, 1(2), 18-41.

Global Reporting Initiative. (2015). Padrões de Relatórios de Sustentabilidade. Recuperado em 15 outubro, 2015, de http://www.globalreporting.org

Global Reporting Initiative. (2016). Padrões de Relatórios de Sustentabilidade. Recuperado em 09 abril, 2016, de http://www.globalreporting.org

Gonçalves, R. S., Weffort, E. F. J., Peleias, I. R., \& Gonçalves, A. O. (2008). Social Evidenciação das empresas brasileiras listadas na NYSE e na BOVESPA: sua relação com os níveis de governança corporativa. Revista Contemporânea de Contabilidade, 1(9), 71-94.

Guimarães, D. A., Rech, I. J., Cunha, M. F., \& Pereira, I. V. (2014). Análise do nível de evidenciação de informações ambientais apresentado pelas empresas abertas que exploram atividades agropecuárias. Revista Evidenciação Contábil \& Finanças, 2(3), 623.

Holanda, A. P., Cardoso, V. I. C., Oliveira, J. D., \& Luca, M. M. M. (2012). Investimentos em responsabilidade social: análise comparativa das empresas concessionárias de serviços públicos e não concessionárias listadas no ISE, da BM\&FBovespa. Pensar contábil, 14(53), 26-34.

Lima, K. P. S., Cunha, D. R., Morreira, F. G. L., \& Porte, M. S. (2012). Contabilidade ambiental: um estudo sobre a evidenciação das informações ambientais nas demonstrações contábeis das grandes empresas brasileiras. Revista Eletrônica de Administração, 11(1), 1-14.

Martins, A. S. R., Quintana, A. C., Jacques, F. V. S., \& Machado, D. P. (2013). O balanço social como instrumento para a sociedade: um estudo na Universidade Federal do Rio Grande. Revista Contemporânea de Contabilidade, 10(19), 49-70.

Mazzioni, S., Di Domenico, D., \& Zanin, A. A evidenciação da prática corporativa de ações de responsabilidade social com o uso do balanço social. (2010). Revista Catarinense da Ciência Contábil, 9(27), 43-59.

Medeiros, A. F., Souza, E. F., Franzin, S. F. L., Almeida, F. M., \& Souza, C. H. M. (2013). Desenvolvimento e Sustentabilidade Ambiental: análise das diretrizes da política nacional de desenvolvimento regional. Linkania, 1(8), 37-57.

Miranda, W. B., \& Malaquias, R. F. (2013). Análise do nível de evidenciação ambiental de empresas brasileiras que negociam ADRS na bolsa de valores de Nova lorque (NYSE). Revista Ambiente Contábil, 5(1), 93-111.

Nobre, F. S., \& Ribeiro, R. E. M. (2013). Cognição e sustentabilidade: estudos de casos múltiplos no Índice de Sustentabilidade Empresarial da BM\&FBovespa. RAC - Revista de Administração Contemporânea, 17(4), 499-517.

Nogueira, E. P.L., \& Faria, A. C. (2012). Sustentabilidade nos principais bancos brasileiros: uma análise sob a ótica da Global Reporting Initiative. Revista Universo Contábil, 8(4), 119139. 
Pereira, G.; Carvalho, F. N., \& Parente, E. G. V. (2011). Desempenho econômico e evidenciação ambiental: análise das empresas que receberam o Prêmio Rumo à Credibilidade 2010. Revista Catarinense de Ciência Contábil, 10(30), 9-26.

Pereira, N. S. P., Pereira, C. A., Monteiro, R. P., \& Paixão, J. M., Filho. (2015). Relatórios de sustentabilidade: ferramenta de interface no desempenho social, econômico e ambiental das organizações. Revista de Auditoria Governança e Contabilidade - RAGC, 3(5), 55-70.

Rodrigues, J. J. M., \& Duarte, M. M. R. F. R. (2011). Relato das responsabilidades social, ambiente e competitividade: enquadramento teórico. Revista Universo Contábil, 7(4), 138-155.

Rosa, F. S., Ensslin, S. R., Ensslin, L., \& Lunkes, R. J. (2011). Gestão da evidenciação ambiental: um estudo sobre as potencialidades e oportunidades do tema. Engenharia Sanitária e Ambiental, 26(1), 157-166.

Santos, A. P. T. (2014). A Sustentabilidade Ambiental dentro das organizações. Revlnter Revista Intertox de Toxicologia, Risco Ambiental e Sociedade, 7(3), 69-100.

Santos, M. S., Silva, T. L., \& Lorandi, J. A. (2014). Evidenciação ambiental - análise da aderência ao relatório de responsabilidade socioambiental da ANEEL pelas companhias do setor elétrico listadas na BM\&FBovespa. Revista Gestão \& Sustentabilidade Ambiental, 2(2) 126-147.

Sartori, S., Ensslin, L., Campo, L. M. S., \& Ensslin, S. R. (2014). Mapeamento do estado da arte do tema sustentabilidade ambiental direcionado para a tecnologia de informação. TransInformação, 26(1), 77-89.

Scarpin, M. R. S., Walter, S. A., Mondini, V. E. D., \& Roncon, A. (2013). Sustentabilidade empresarial: análise de caso à luz da teoria da estratégia como pratica. Revista de Gestão Social e Ambiental, 7(2), 87-100.

Siche, R., Agostinho, F., Ortega, E., \& Romeiro, A. (2007). Índices versus indicadores: precisões conceituais na discussão da sustentabilidade de países. Ambiente \& Sociedade, 10(2), 137-148.

Silva, T. L., Vicente, E. F. R., Pfitscher, E. D., \& Rosa, F. S. (2013). Environmental Disclosureinformações sobre resíduos sólidos divulgadas pelas empresas potencialmente poluidoras listadas na BM\&FBOVESPA. Revista Ambiente Contábil, 5(2), 229-249.

Tomé, I. M., \& Bresciani, L. P. (2015). Explicitação e análise de modelos de sustentabilidade de empresas de gestão ambiental baseados em MORPH. Revista de Administração, Contabilidade e Sustentabilidade, 5(1), 21-38. 